\title{
The Effect of Counteranions in the Polymerization of Isobutyl Vinyl Ether Initiated by Triphenylmethyl Cation*
}

\author{
Toyoki Kunitake, Yoshihiko Matsuguma, and Chuji Aso \\ Department of Organic Synthesis, Faculty of Engineering, \\ Kyushu University, Fukuoka, 812, Japan.
}

(Received November 16, 1970)

\begin{abstract}
The cationic polymerization of isobutyl vinyl ether was carried out at $-75^{\circ} \mathrm{C}$ by using triphenylmethyl salts $\left(\mathrm{Ph}_{3} \mathrm{C}^{+} \mathrm{X}^{-}, \mathrm{X}^{-}=\mathrm{BF}_{4}^{-}, \mathrm{AlCl}_{4}^{-}, \mathrm{AlBr}_{4}^{-}, \mathrm{SbCl}_{6}{ }^{-}\right.$and $\mathrm{SnCl}_{5}^{-}$) as initiator. The polymer was shown to contain the triphenylmethyl group. The extent of chain transfer, determined from the content of the triphenylmethyl group, was $0-4.4$ in all the systems studied. These values are much smaller than those reported with $\mathrm{BF}_{3} \mathrm{OEt}_{2}$. The steric structure of the polymer was inferred from the precipitation temperature of the polymer in methyl ethyl ketone, $T_{\mathrm{p}}$, as suggested by Okamura, et al. $T_{\mathrm{p}}$ decreased with increasing polarity of polymerization solvents. In less polar media, $T_{\mathrm{p}}$ decreased in the following order
\end{abstract}

$$
\mathrm{SnCl}_{5}^{-}>\mathrm{SbCl}_{6}{ }^{-} \sim \mathrm{AlBr}_{4}^{-}>\mathrm{AlCl}_{4}{ }^{-}>\mathrm{BF}_{4}{ }^{-} \text {. }
$$

The observed order of $T_{\mathrm{p}}$ agreed with that of anion sizes, except for $\mathrm{SnCl}_{5}{ }^{-}$. Thus it is suggested that the steric effect of the counteranion is an important factor in deciding the steric course of propagation for tight ion-pairs. These results were explained within the framework of the steric course of the cationic propagation which we had proposed previously.

KEY WORDS Cationic Polymerization/Poly(Isobutyl Vinyl Ether)/ Steric Structure/Counteranion/Triphenylmethyl Salts/Chain Transfer/ Steric Course/

In the propagation step of ionic polymerizations of vinyl monomers, it is expected that counterions exert strong influences on the behavior of the propagating species. In the cationic polymerization, it is as yet difficult to interpret the propagation data in a unified way in terms of the nature of the growing species, in contrast with the "living" anionic polymerization. ${ }^{1}$ This may be ascribed in a large part to the fact that the structure of the growing species is generally not defined clearly in the cationic polymerization.

Thus it becomes attractive to study cationic polymerization by using catalysts or initiators which would form well-defined growing species. Triphenylmethyl salts have been known to initiate the cationic polymerization of several vinyl and

\footnotetext{
* Presented in part at the 19th annual meeting of the Society of Polymer Science, Japan, Tokyo, May 1970. Contribution No. 226 from this department. This is Part II in the series of "Mechanism of Cationic Polymerizations." For Part I in this series, see ref 11 .
}

related monomers. ${ }^{2-10}$ In these cases, the metal halide anion would become a part of the growing species without changing its structure, and the reactivity of the growing ion-pair may be discussed in a more straightforward way than in polymerizations with, say, Lewis acids. We therefore prepared several triphenylmethyl salts and carried out polymerizations of isobutyl vinyl ether. Particular attention was directed to the incorporation of the triphenylmethyl group into polymer and the influence of polymerization conditions on the steric structure of the polymer. The variation of the steric structure was interpreted in terms of the mechanism on the steric course of propagation which we recently proposed. ${ }^{11}$

\section{EXPERIMENTAL}

\section{Materials}

Commercial isobutyl vinyl ether (1st grade) was washed with aqueous alkali, dried over $\mathrm{KOH}$ 
pellets, refluxed over sodium metal and distilled. It was redistilled from $\mathrm{Na}$ metal just before use: bp $82.7-83.0^{\circ} \mathrm{C}$. Polymerization solvents were purified according to the common procedures and stored over molecular sieves.

\section{Preparations of Triphenylmethyl Salts}

Triphenylmethyl alcohol was prepared by the Grignard reaction of phenylmagnesium bromide and ethyl benzoate and by the Friedel-Crafts reaction of benzene and carbon tetrachloride with an $\mathrm{AlCl}_{3}$ catalyst, and recrystalliżed from $\mathrm{CCl}_{4}$ : $\mathrm{mp} 163.6-165.0^{\circ} \mathrm{C}$ (lit. ${ }^{12} \mathrm{mp} 162.5^{\circ} \mathrm{C}$ ). Triphenylmethyl chloride was obtained by reaction of triphenylmethyl alcohol and acetyl chloride in benzene and recrystallized from benzene: $\mathrm{mp} 109.2-111.1^{\circ} \mathrm{C}\left(\right.$ lit. $\left.^{13} \mathrm{mp} 111-112^{\circ} \mathrm{C}\right)$. Triphenylmethyl bromide was similarly prepared from triphenylmethyl alcohol and acetyl bromide in benzene: $\mathrm{mp} 155.0-156.2^{\circ} \mathrm{C}$ (lit. ${ }^{14} \mathrm{mp} 153-$ $\left.154^{\circ} \mathrm{C}\right)$.

Triphenylmethyl fluoroborate was prepared as described previously. ${ }^{8}$ Other triphenylmethyl salts were prepared by mixing metal halides and triphenylmethyl halides $(20 \mathrm{~mol} \%$ excess $)$ in benzene or in $\mathrm{CCl}_{4}$ under nitrogen. Yellow to orange precipitates formed were filtered, washed with dry ether, and dried in vacuo. The yields were nearly quantitative. Table I summarizes some data on the characterization of these salts. The agreement of some of the carbon content was not satisfactory. However, further attempts at purification by recrystallization did not give better results, since these salts were sensitive to moisture.

All the salts showed characteristic infrared peaks of the triphenylmethyl cation at 15801590,1360 , and $1300 \mathrm{~cm}^{-1} .^{15}$ Some of the characteristic peaks of the anions are given in Table I. Ultraviolet spectra of these salts in $70-\%$ sulfuric acid possessed a peak at $433 \mathrm{~m} \mu$ with extinction coefficients of 36000-38000, in agreement with the literature value. ${ }^{21,22}$ NMR spectra of these five salts in ethylene dichloride or in acetonitrile showed an identical multiplet due to the phenyl proton at around $8 \mathrm{ppm}$. The chemical shifts of the phenyl proton of the triphenylmethyl cation in chlorosulfonic acid have been determined: $7.69 \mathrm{ppm}$ (ortho proton), 7.87 ppm (meta proton), $8.24 \mathrm{ppm}$ (para proton). ${ }^{23}$ The present NMR data were similarly analyzed to give the chemical shift of $7.70 \pm 0.02,7.89 \pm$ 0.01 , and $8.30 \pm 0.03 \mathrm{ppm}$ for the ortho, meta, and para protons, respectively. The agreements with the literature value are satisfactory. The phenyl proton due to triphenylmethyl halides (sharp singlet, $7.25 \mathrm{ppm}$ ) or triphenylmethyl alcohol (sharp singlet, $7.24 \mathrm{ppm}$ ) was not detected in these spectra. An NMR spectrum of $\mathrm{Ph}_{3} \mathrm{C}^{+}$$\mathrm{AlBr}_{4}{ }^{-}$in a $6: 4$ mixture of ethylene dichloride and $n$-hexane showed a similar phenyl multiplet, although its resolution was lower because of the limited solubility.

\section{Polymerization}

Polymerizations were conducted in glassstoppered ampoules with side-arm for nitrogen inlet. The ampoule was flamed and flushed with

Table I. Triphenylmethyl salts

\begin{tabular}{|c|c|c|c|c|c|}
\hline \multirow{2}{*}{ Compounds } & \multicolumn{2}{|c|}{ Elemental analysis ${ }^{a}$} & \multirow{2}{*}{\multicolumn{2}{|c|}{$\mathrm{mp},{ }^{\circ} \mathrm{C}$}} & \multirow{2}{*}{ Infrared peak, $\mathrm{cm}^{-1}$} \\
\hline & Carbon, $\%$ & Hydrogen, $\%$ & & & \\
\hline \multirow[t]{2}{*}{$\left(\mathrm{C}_{6} \mathrm{H}_{5}\right)_{3} \mathrm{CAlCl}_{4}$} & 53.16 & 3.91 & & $150-160(\mathrm{dec})$ & 499 \\
\hline & $(55.37)$ & $(3.67)$ & lit. ${ }^{16}$ & $164-166$ & lit. ${ }^{16} 496,525\left(\mathrm{Ph}_{3} \mathrm{CAlCl}_{4}\right)$ \\
\hline$\left(\mathrm{C}_{6} \mathrm{H}_{5}\right)_{3} \mathrm{CSnCl}_{5}$ & $\begin{array}{c}42.05 \\
(42.32)\end{array}$ & $\begin{array}{c}2.89 \\
(2.80)\end{array}$ & & $160.0-162.3(\mathrm{dec})$ & - \\
\hline \multirow[t]{2}{*}{$\left(\mathrm{C}_{6} \mathrm{H}_{5}\right)_{3} \mathrm{CSbCl}_{6}$} & 39.38 & 2.68 & & $197.6-198.6(\mathrm{dec})$ & 337 (broad) \\
\hline & $(39.50)$ & $(2.62)$ & lit. ${ }^{17}$ & $220(\mathrm{dec})$ & lit. ${ }^{18} 336\left(\mathrm{C}_{5} \mathrm{H}_{6} \mathrm{NSbCl}_{6}\right)$ \\
\hline \multirow[t]{2}{*}{$\left(\mathrm{C}_{6} \mathrm{H}_{5}\right)_{3} \mathrm{CAlBr}_{4}$} & 37.90 & 2.93 & & $160-166(\mathrm{dec})$ & - \\
\hline & $(38.68)$ & $(2.56)$ & lit. ${ }^{19}$ & $120-123$ & \\
\hline$\left(\mathrm{C}_{6} \mathrm{H}_{5}\right)_{3} \mathrm{CBF}_{4}$ & $\begin{array}{c}68.45 \\
(69.13)\end{array}$ & $\begin{array}{c}4.64 \\
(4.58)\end{array}$ & & $179-180(\mathrm{dec})$ & $\begin{array}{l}1053,520 \\
\text { lit. }^{20} \quad 1052,527,519\left(\mathrm{CH}_{3} \mathrm{COBF}_{4}\right)\end{array}$ \\
\hline
\end{tabular}

a The data in parentheses are theoretical values. 


\section{Cationic Polymerization of Isobutyl Vinyl Ether}

dry nitrogen. A given amount of a triphenylmethyl salt and $40 \mathrm{ml}$ of solvent were placed in the ampoule under nitrogen and stirred magnetically at $-75^{\circ} \mathrm{C}$. Polymerization was initiated by adding a precooled mixture of monomer $(2 \mathrm{~m} l)$ and solvent $(10 \mathrm{~m} l)$. After a given period, a small amount of ammoniacal methanol was added and then the mixture was poured into excess methanol. When a large amount of $n$ hexane was used as solvent, solvents were evaporated after termination, and the residue redissolved in methylene chloride was poured into excess methanol. The polymer was separated by decantation, washed well with methanol and dried in vacuo at $50^{\circ} \mathrm{C}$. Reprecipitations were repeated (usually $1-2$ times) from methylene chloride and methanol, until the spot other than that of the polymer was not detected by thinlayer chromatographic analysis.

\section{Thin-Layer Chromatography}

Samples were developed with $\mathrm{CHCl}_{3}$ on a silica-gel thin-layer and dried. With the terminated polymerization mixture, spots corresponding to triphenylmethyl alcohol and methyl triphenylmethyl ether appeared at $R_{\mathrm{f}}=0.65$ and 0.95 , respectively, by spraying $\mathrm{SnCl}_{4}$ in $\mathrm{CH}_{2} \mathrm{Cl}_{2}$. The latter spot was observed only in a few cases. These compounds are probably derived from the unreacted initiator molecule upon termination with ammoniacal methanol. The formation of methyl triphenylmethyl ether was confirmed by its isolation from a reaction mixture of triphenylmethyl fluoroborate with ammoniacal methanol: $\mathrm{mp} 81.9-82.5^{\circ} \mathrm{C}\left(\right.$ lit. $\left.^{14} 83-84^{\circ} \mathrm{C}\right)$. The polymer remained at the original place, as confirmed by discoloration with iodine. The spot of triphenylmethyl alcohol was not discernible when its amount was less than $0.17 \mathrm{wt} \%$ of the polymer. This lower limit corresponds to one triphenylmethyl alcohol molecule per 1500 monomer units.

\section{Determination of the Triphenylmethyl Group in Polymer}

The triphenylmethyl group incorporated into polymer was determined from the ultraviolet absorption of the benzene ring at $260 \mathrm{~m} \mu$. Approximately $0.6-\mathrm{wt} \%$ polymer solution in ethylene dichloride was used. The extinction coefficient of the triphenylmethyl group in polymer was assumed to be the same as that of triphenyl- methyl alcohol, $\varepsilon_{\max }(260 \mathrm{~m} \mu)=645$. The molecular weight of the polymers obtained in $n$ hexane- $\mathrm{CH}_{2} \mathrm{Cl}_{2}(80 / 20)$ solvent was greater than those in other solvents, and the content of the triphenylmethyl group could not be determined accurately for these polymers. An IR peak at $700 \mathrm{~cm}^{-1}$ was commonly noted for polymers of $[\eta] \leq 0.5$. This peak is ascribed to the phenyl group, further supporting the presence of the triphenylmethyl group.

\section{Instruments}

The number-average molecular weight $\bar{M}_{n}$ was measured in benzene at $37^{\circ} \mathrm{C}$ by a vapor pressure osmometer (Mechrolab Model 301A). Viscosities were determined in benzene at $30^{\circ} \mathrm{C}$ using a modified Ubbelohde viscometer. NMR spectra were obtained with a Varian A60 instrument by using tetramethylsilane as internal standard. Infrared and ultraviolet spectra were measured by JASCO IR-E and Bausch \& Lomb Spectronic 505 spectrometers, respectively. Far-infrared spectra were obtained as nujol mulls with a Hitachi EPI-L grating spectrometer.

\section{RESULTS}

Table II summarizes polymerization results of isobutyl vinyl ether at $-75^{\circ} \mathrm{C}$. The initiators used were $\mathrm{BF}_{3} \mathrm{OEt}_{2}$ and five triphenylmethyl salts. Solvent systems used were $n$-hexane- $-\mathrm{CH}_{2} \mathrm{Cl}_{2}$ ( $80 / 20$ by volume), $n$-hexane- $\mathrm{CH}_{2} \mathrm{Cl}_{2}(50 / 50)$, $\mathrm{CH}_{2} \mathrm{Cl}_{2}$, and $\mathrm{CH}_{2} \mathrm{Cl}_{2}-\mathrm{CH}_{3} \mathrm{CN}(70 / 30)$, in the order of increasing medium polarity. The polymerization was generally fast, and, except for $n$ hexane $-\mathrm{CH}_{2} \mathrm{Cl}_{2}(80 / 20)$ solvent, high conversions were attained in 5-10 minutes with any catalyst. Longer polymerization periods were necessary in $n$-hexane- $\mathrm{CH}_{2} \mathrm{Cl}_{2}(80 / 20)$ medium.

The triphenylmethyl salts used were not completely soluble in mixtures of $n$-hexane and $\mathrm{CH}_{2} \mathrm{Cl}_{2}$. In $100 \%$-hexane triphenylmethyl salts were not soluble at all and the solvent remained colorless. The polymerization in $n$-hexane$\mathrm{CH}_{2} \mathrm{Cl}_{2}$ mixtures probably started from dissolved initiator molecules, since no polymerization occurred in the $100 \% n$-hexane medium after 15 hr with the most active $\mathrm{Ph}_{3} \mathrm{C}^{+} \mathrm{AlCl}_{4}^{-}$initiator.

In $n$-hexane- $\mathrm{CH}_{2} \mathrm{Cl}_{2}(80 / 20)$ media, swollen polymers were partly or wholly separated in several cases (Table II, No. 3, 4, 6, and 7), and, 
Table II. Polymerization of isobutyl vinyl ether ${ }^{a}$

\begin{tabular}{|c|c|c|c|c|c|c|}
\hline \multirow{2}{*}{$\frac{\text { No. }}{1^{\ominus}}$} & \multicolumn{2}{|c|}{ Initiator $^{\mathrm{b}}, \mathrm{mol} / \mathrm{l}$} & \multirow{2}{*}{$\frac{\text { Solvent }^{\mathrm{c}}}{\mathrm{I}}$} & \multirow{2}{*}{$\frac{\begin{array}{c}\text { Polymerization } \\
\text { time, min }\end{array}}{60}$} & \multirow{2}{*}{$\frac{\begin{array}{c}\text { Conversion, } \\
\%\end{array}}{100}$} & \multirow{2}{*}{$\frac{[\eta]^{\mathrm{d}}, \mathrm{d} l / \mathrm{g}}{1.10}$} \\
\hline & $\mathrm{BF}_{3} \mathrm{OEt}_{2}$ & $8.6 \times 10^{-3}$ & & & & \\
\hline 2 & $\mathrm{Ph}_{3} \mathrm{C}^{+} \mathrm{AlBr}_{4}^{-}$ & $3.0 \times 10^{-3}$ & I & 200 & 67.1 & 0.350 \\
\hline $3^{\mathrm{f}}$ & $\mathrm{Ph}_{3} \mathrm{C}^{+} \mathrm{AlCl}_{4}^{-}$ & $8.7 \times 10^{-3}$ & I & 60 & $95.3 \mathrm{~g}$ & 1.07 \\
\hline 4 & $\mathrm{Ph}_{3} \mathrm{C}^{+} \mathrm{AlCl}_{4}^{-}$ & $4.6 \times 10^{-3}$ & I & 12 & $75.3^{\mathrm{h}}$ & 0.940 \\
\hline 5 & $\mathrm{Ph}_{3} \mathrm{C}^{+} \mathrm{BF}_{4}^{-}$ & $8.1 \times 10^{-3}$ & I & 125 & 93.5 & 0.478 \\
\hline 6 & $\mathrm{Ph}_{3} \mathrm{C}^{+} \mathrm{SbCl}_{6}-$ & $7.1 \times 10^{-3}$ & I & 60 & $94.6 \mathrm{~g}$ & 0.980 \\
\hline 7 & $\mathrm{Ph}_{3} \mathrm{C}^{+} \mathrm{SbCl}_{6}{ }^{-}$ & $3.4 \times 10^{-3}$ & I & 65 & $86.1^{\mathrm{h}}$ & 0.816 \\
\hline 8 & $\mathrm{Ph}_{3} \mathrm{C}^{+} \mathrm{SnCl}_{5}^{-}$ & $7.9 \times 10^{-3}$ & I & 135 & 100 & 0.324 \\
\hline 9 & $\mathrm{Ph}_{3} \mathrm{C}^{+} \mathrm{AlBr}_{4}^{-}$ & $8.4 \times 10^{-3}$ & II & 10 & 91.6 & 0.250 \\
\hline 10 & $\mathrm{Ph}_{3} \mathrm{C}^{+} \mathrm{AlCl}_{4}^{-}$ & $8.3 \times 10^{-3}$ & II & 10 & 89.1 & 0.315 \\
\hline 11 & $\mathrm{Ph}_{3} \mathrm{C}^{+} \mathrm{BF}_{4}^{--}$ & $9.8 \times 10^{-3}$ & II & 10 & 92.4 & 0.294 \\
\hline 12 & $\mathrm{Ph}_{3} \mathrm{C}^{+} \mathrm{SbCl}_{6}^{-}$ & $4.9 \times 10^{-3}$ & II & 10 & 88.1 & 0.292 \\
\hline 13 & $\mathrm{Ph}_{3} \mathrm{C}^{+} \mathrm{SnCl}_{5}^{-}$ & $8.8 \times 10^{-3}$ & II & 10 & 89.8 & 0.184 \\
\hline 14 & $\mathrm{Ph}_{3} \mathrm{C}^{+} \mathrm{AlCl}_{4}^{-}$ & $2.1 \times 10^{-2}$ & III & 10 & 93.9 & 0.245 \\
\hline 15 & $\mathrm{Ph}_{3} \mathrm{C}^{+} \mathrm{BF}_{4}^{-}$ & $2.5 \times 10^{-2}$ & III & 10 & 88.8 & 0.245 \\
\hline 16 & $\mathrm{Ph}_{3} \mathrm{C}^{+} \mathrm{SbCl}_{6}{ }^{-}$ & $2.4 \times 10^{-2}$ & III & 10 & 91.6 & 0.172 \\
\hline 17 & $\mathrm{Ph}_{3} \mathrm{C}^{+} \mathrm{SnCl}_{5}-$ & $2.5 \times 10^{-2}$ & III & 10 & 84.4 & 0.143 \\
\hline 18 & $\mathrm{Ph}_{3} \mathrm{C}^{+} \mathrm{AlCl}_{4}^{-}$ & $2.6 \times 10^{-2}$ & IV & 5 & $68.6^{g}$ & 0.234 \\
\hline 19 & $\mathrm{Ph}_{3} \mathrm{C}^{+} \mathrm{BF}_{4}^{-}$ & $2.3 \times 10^{-2}$ & IV & 5 & $98.8 \mathrm{~g}$ & 0.170 \\
\hline 20 & $\mathrm{Ph}_{3} \mathrm{C}^{+} \mathrm{SbCl}_{6}{ }^{-}$ & $2.4 \times 10^{-2}$ & IV & 5 & $78.6 \mathrm{~s}$ & 0.122 \\
\hline 21 & $\mathrm{Ph}_{3} \mathrm{C}^{+} \mathrm{SnCl}_{5}^{-}$ & $2.5 \times 10^{-2}$ & IV & 5 & $79.7^{\mathrm{g}}$ & 0.068 \\
\hline
\end{tabular}

a $-75^{\circ} \mathrm{C}$; monomer concentration, $0.271 \mathrm{~mol} / l$.

b Initiators not completely soluble in solvents I and II.

c Solvent $\mathrm{I}, n$-hexane- $\mathrm{CH}_{2} \mathrm{Cl}_{2}$ (8:2 by volume); Solvent II, $n$-hexane- $\mathrm{CH}_{2} \mathrm{Cl}_{2}$ (5:5 by volume); Solvent

III, $\mathrm{CH}_{2} \mathrm{Cl}_{2}$; Solvent IV, $\mathrm{CH}_{2} \mathrm{Cl}_{2}-\mathrm{CH}_{3} \mathrm{CN}$ ( $7: 3$ by volume).

d $30^{\circ} \mathrm{C}$ in benzene.

e Monomer concentration, $0.303 \mathrm{~mol} / \mathrm{l}$.

f Monomer concentration, $0.216 \mathrm{~mol} / l$.

g Polymer precipitated during polymerization.

h Polymer precipitated partially during polymerization.

in $\mathrm{CH}_{2} \mathrm{Cl}_{2}-\mathrm{CH}_{3} \mathrm{CN}$ solvent, rubbery polymers precipitated instantaneously upon addition of monomer solutions.

The precipitation temperature of the polymer, $T_{\mathrm{p}}$, was measured in methyl ethyl ketone $(0.5-$ $\mathrm{w} / \mathrm{v} \%$ solution) according to the procedure of Okamura, et al. ${ }^{24}$ In order to obtain accurate $T_{\mathrm{p}}$ data, the solution was maintained at temperatures around $T_{\mathrm{p}}$, and warming and cooling were carried out as slowly as possible. The reproducibility of $T_{\mathrm{p}}$ was better than $\pm 0.5^{\circ} \mathrm{C}$ for any single sample.

The variation of $T_{\mathrm{p}}$ with polymerization conditions is shown in Figure 1. The $T_{\mathrm{p}}$ value decreased with increasing polarity of the polymerization medium, and, in polar media $\left(\mathrm{CH}_{2} \mathrm{Cl}_{2}\right.$, $\mathrm{CH}_{2} \mathrm{Cl}_{2}-\mathrm{CH}_{3} \mathrm{CN}$ ), it was $-50 \pm 5^{\circ} \mathrm{C}$ for any initiator except for $\mathrm{Ph}_{3} \mathrm{C}^{+} \mathrm{SnCl}_{5}{ }^{-}$. The particularly low $T_{\mathrm{p}}$ value $\left(<-70^{\circ} \mathrm{C}\right)$ in Table II, No. $21\left(\mathrm{SnCl}_{5}{ }^{-}, \mathrm{CH}_{2} \mathrm{Cl}_{2}-\mathrm{CH}_{3} \mathrm{CN}\right)$ may be ascribed to the low molecular weight of the polymer $([\eta]=0.068 \mathrm{~d} l / g)$. In $n$-hexane $-\mathrm{CH}_{2} \mathrm{Cl}_{2}, T_{\mathrm{p}}$ varied from $c a$. $-40^{\circ} \mathrm{C}$ to $-5^{\circ} \mathrm{C}$, and was characteristically dependent on the initiator used. This variation can be ascribed to the counteranion effect as discussed later.

In Table III are compared the number-average molecular weight and the number of the monomer unit per triphenylmethyl group incorporated. The comparison was made only for polymers of relatively low molecular weight. The average number of chain transfers calculated from these data ranged from 0 to 4.4 . 
Cationic Polymerization of Isobutyl Vinyl Ether

Table III. Content of the triphenylmethyl group in polymer

\begin{tabular}{clcccc}
\hline No. ${ }^{\mathrm{a}}$ & Initiator & Solvent ${ }^{\mathrm{b}}$ & $\begin{array}{c}\text { Number-average } \\
\text { degree of poly- } \\
\text { merization }{ }^{\mathrm{c}}, \overline{\boldsymbol{P}}_{n}\end{array}$ & $\begin{array}{c}\text { Number of monomer } \\
\text { unit per } \mathrm{Ph}_{3} \mathrm{C} \\
\text { group incorporated }\end{array}$ & $\begin{array}{c}\text { Number of } \\
\text { chain transfer } \\
\text { per initiation }\end{array}$ \\
\hline 10 & $\mathrm{Ph}_{3} \mathrm{C}^{+} \mathrm{AlCl}_{4}{ }^{-}$ & II & 227 & 530 & $1.3 \pm 0.4$ \\
11 & $\mathrm{Ph}_{3} \mathrm{C}^{+} \mathrm{BF}_{4}^{-}$ & II & 240 & 326 & $0.4 \pm 0.2$ \\
13 & $\mathrm{Ph}_{3} \mathrm{C}^{+} \mathrm{SnCl}_{5}{ }^{-}$ & II & 134 & 237 & $0.8 \pm 0.4$ \\
14 & $\mathrm{Ph}_{3} \mathrm{C}^{+} \mathrm{AlCl}_{4}^{-}$ & III & 167 & 396 & $1.4 \pm 0.5$ \\
15 & $\mathrm{Ph}_{3} \mathrm{C}^{+} \mathrm{BF}_{4}^{-}$ & III & 175 & 410 & $1.3 \pm 0.4$ \\
16 & $\mathrm{Ph}_{3} \mathrm{C}^{+} \mathrm{SbCl}_{6}{ }^{-}$ & III & 154 & 420 & $1.7 \pm 0.8$ \\
17 & $\mathrm{Ph}_{3} \mathrm{C}^{+} \mathrm{SnCl}_{5}^{-}$ & III & 130 & 170 & $0.4 \pm 0.4$ \\
18 & $\mathrm{Ph}_{3} \mathrm{C}^{+} \mathrm{AlCl}_{4}^{-}$ & IV & 161 & 220 & $0.4 \pm 0.3$ \\
19 & $\mathrm{Ph}_{3} \mathrm{C}^{+} \mathrm{BF}_{4}^{-}$ & IV & 142 & 320 & $1.3 \pm 0.4$ \\
20 & $\mathrm{Ph}_{3} \mathrm{C}^{+} \mathrm{SbCl}_{6}{ }^{-}$ & IV & 84 & 455 & $4.4 \pm 0.8$ \\
21 & $\mathrm{Ph}_{3} \mathrm{C}^{+} \mathrm{SnCl}_{5}^{-}$ & IV & 57 & 57 & $0.1 \pm 0.1$ \\
\hline
\end{tabular}

a Run numbers correspond to those of Table II.

b See Table II, footnote c.

c Determined by vapor pressure osmometry.

d $\left\{\left[\frac{\text { Monomer unit }}{\mathrm{Ph}_{3} \mathrm{C}}\right] / \bar{P}_{n}\right\}-1$ The error was estimated from the reliability of determinations of molecular weight and the triphenylmethyl content.

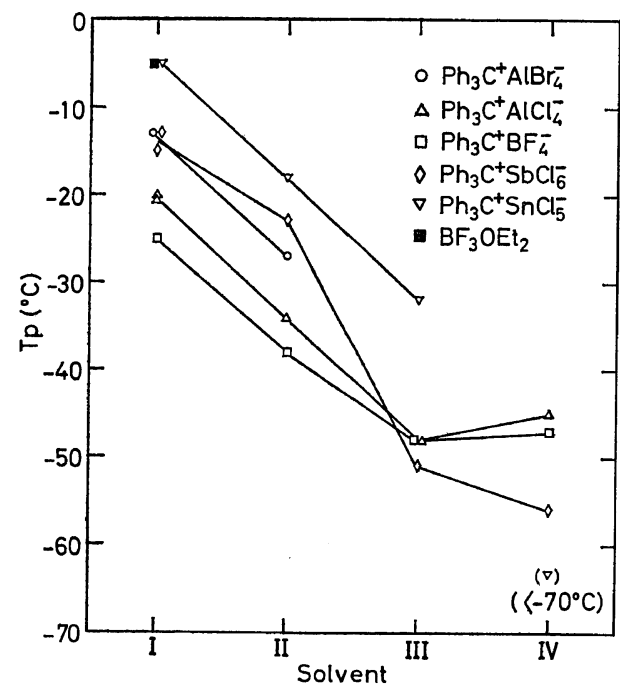

Figure 1. Variation of the precipitation temperature with polymerization conditions. Solvent: I, $n$ hexane- $\mathrm{CH}_{2} \mathrm{Cl}_{2}(8: 2) ; \mathrm{II}, n$-hexane- $\mathrm{CH}_{2} \mathrm{Cl}_{2}$ (5:5); III, $\mathrm{CH}_{2} \mathrm{Cl}_{2} ; \mathrm{IV}, \mathrm{CH}_{2} \mathrm{Cl}_{2}-\mathrm{CH}_{3} \mathrm{CN}(7: 3)$. The $T_{\mathrm{p}}$ value of the polymer obtained with $\mathrm{Ph}_{3} \mathrm{C}^{+} \mathrm{SnCl}_{5}-$ in solvent IV was below $-70^{\circ} \mathrm{C}$.

\section{DISCUSSION}

\section{Initiation and Chain Transfer}

In some of the cationic polymerization with triphenylmethyl salts, the salt was considered to be in equilibrium with triphenylmethyl halide and metal halide. ${ }^{5-7}$

$$
\left(\mathrm{C}_{6} \mathrm{H}_{5}\right)_{3} \mathrm{C}^{+} \mathrm{MX}_{n}{ }^{-} \rightleftarrows\left(\mathrm{C}_{6} \mathrm{H}_{5}\right)_{3} \mathrm{CX}+\mathrm{MX}_{n-1}
$$

There is a possibility that metal halides (Lewis acids) formed would also be capable of initiating polymerization with combination of water and other contaminants. However, the NMR data is consistent with the triphenylmethyl cation structure, as mentioned above, indicating that the dissociation of the salts was negligible. Though the NMR data do not exclude the possibility that triphenylmethyl salts might dissociate at catalyst concentrations $\left(2.5 \times 10^{-2}-3.0 \times 10^{-3} \mathrm{~mol} /\right.$ $l$ ), polymerization started only when the reaction mixture turned yellow to orange due to dissolution of triphenylmethyl salts. Furthermore, the triphenylmethyl group was detected in polymer in considerable amounts. Thus, it was concluded that polymerization was initiated in the main through addition of triphenylmethyl cation to the monomer molecule.

$$
\begin{aligned}
& \begin{array}{r}
\left(\mathrm{C}_{6} \mathrm{H}_{5}\right)_{3} \mathrm{C}^{+} \mathrm{MX}_{n}{ }^{-}+\mathrm{CH}_{2}=\underset{\mathrm{O}}{\mathrm{CH}} \\
\mathrm{O}
\end{array} \\
& i \mathrm{Bu}
\end{aligned}
$$

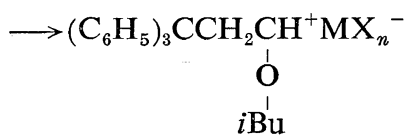


In the polymerization of isobutyl vinyl ether with $\mathrm{BF}_{3} \mathrm{O}\left({ }^{14} \mathrm{C}_{2} \mathrm{H}_{5}\right)_{2}$ in liquid propane, Kennedy determined the number of chain transfers per initiator involved to be 140 from the content of the radioactive carbon in polymer. ${ }^{25}$ This value is much greater than those observed here with triphenylmethyl salts. It was also shown that the chain transfer was negligible in the polymerization of cyclopentadiene with $\mathrm{Ph}_{3} \mathrm{C}^{+} \mathrm{SbCl}_{6}{ }^{-}$initiator ${ }^{10}$ and with $\mathrm{Ph}_{3} \mathrm{C}^{+} \mathrm{BF}_{4}^{-}$initiator. ${ }^{26}$ The discrepancy in the number of chain transfers between $\mathrm{BF}_{3} \mathrm{OEt}_{2}$ and triphenylmethyl salts is interesting. Greater stability of the counteranion of the triphenylmethyl salts relative to that derived from $\mathrm{BF}_{3} \mathrm{OEt}_{2}$ appears to be related to the decreased tendency of chain transfer.

The transfer agent involved in the present system is not yet clear. It might involve monomer, solvent, and/or contaminating water. The growing carbonium ion would not react with the triphenylmethyl cation.

\section{Counteranion and Steric Course of Propagation}

The crystalline poly(isobutyl vinyl ether) was obtained for the first time by Schildknecht, et al., with a $\mathrm{BF}_{3} \mathrm{OEt}_{2}$ catalyst. ${ }^{27}$ Subsequently, Okamura, et al., established from comparisons of $T_{\mathrm{p}}$ and other physical properties (X-ray crystallinity and Young's modulus) that $T_{\mathrm{p}}$ depended essentially on the steric structure (isotacticity) of the polymer. ${ }^{24}$ This is also supported by the IR study of the polymer. Iwasaki ${ }^{28}$ found IR peaks characteristic of the crystalline isotactic polymer. New IR peaks appeared at 985 and $1340 \mathrm{~cm}^{-1}$ in the crystalline polymer and a peak observed at $820 \mathrm{~cm}^{-1}$ for the amorphous polymer disappeared in the crystalline polymer. A similar IR observation was made between polymers of high and low $T_{\mathrm{p}}$ values in the present study, and the variation of the intensity of these peaks correlated qualitatively with $T_{\mathrm{p}}$ values. Therefore, we used the $T_{\mathrm{p}}$ value as a measure of isotacticity in the following discussion.

The isotacticity of poly(isobutyl vinyl ether) estimated from $T_{\mathrm{p}}$ was shown to be not necessarily affected by whether the polymerization system was homogeneous or not. ${ }^{24}$ Similarly, in our systems, heterogeneity of the polymerization system per se appears not to affect $T_{\mathrm{p}}$ for the following reasons: (1) Polymerization was initiated by dissolved triphenylmethyl salts, as mentioned above; (2) The $T_{\mathrm{p}}$ values were similar for a given initiator in $\mathrm{CH}_{2} \mathrm{Cl}_{2}$ and in the $\mathrm{CH}_{2} \mathrm{Cl}_{2}-\mathrm{CH}_{3} \mathrm{CN}$ mixture $\left(\mathrm{Ph}_{3} \mathrm{C}^{+} \mathrm{SnCl}_{5}{ }^{-}\right.$excluded $)$, in spite of the fact that the polymers invariably precipitated during polymerization in the $\mathrm{CH}_{2} \mathrm{Cl}_{2}$ $-\mathrm{CH}_{3} \mathrm{CN}$ solvent while no precipitation occurred in $\mathrm{CH}_{2} \mathrm{Cl}_{2}$.

Thus, the variation of $T_{p}$ must be related to the nature of the growing carbonium ion-pair. Previously, Okamura, et al., carried out cationic polymerizations of isobutyl vinyl ether with Lewis acids, ${ }^{24,29}$ and found that the isotacticity decreased with increasing polarity of solvent, and that $\mathrm{BF}_{3} \mathrm{OEt}_{2}$ gave polymers of higher isotacticity than $\mathrm{SnCl}_{4}$.

Recently we made a proposal on the steric course of propagation of vinyl and related monomers which proceeds via simple carbonium ionpairs. ${ }^{11}$

In this scheme, the most stable conformation of the last two units was assumed to be such as shown by I, and the front-side (less-hindered site) attack to the carbonium ion gives rise to a syndiotactic placement (eq 3 ) and the backside attack an isotactic placement (eq 4).

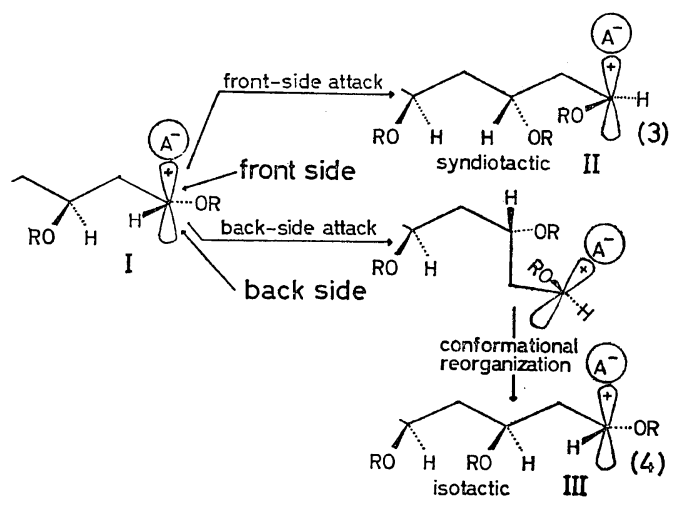

The isotactic propagation of vinyl ether including isobutyl vinyl ether in nonpolar media can be satisfactorily explained by this scheme in terms of the back-side attack. The tightness of the growing ion-pair is lessened in polar media and the back-side attack becomes less favored. The relatively close, low $T_{\mathrm{p}}$ values of the polymers obtained in polar solvent systems like $\mathrm{CH}_{2} \mathrm{Cl}_{2}$ and $\mathrm{CH}_{2} \mathrm{Cl}_{2}-\mathrm{CH}_{3} \mathrm{CN}$ (except for run no. 17 and 21) suggest that the effect of the counteranion 
on the steric course of propagation was small in theses media.

The dependency of $T_{\mathrm{p}}$ upon initiators was more obvious in less polar polymerization solvents ( $n$-hexane- $\mathrm{CH}_{2} \mathrm{Cl}_{2}$ mixtures), and $T_{\mathrm{p}}$ increased in the following order of the counteranion.

(anion from $\mathrm{BF}_{3} \mathrm{OEt}_{2}$ ), $\mathrm{SnCl}_{5}^{-}>$

$$
\mathrm{SbCl}_{6}{ }^{-} \sim \mathrm{AlBr}_{4}{ }^{-}>\mathrm{AlCl}_{4}{ }^{-}>\mathrm{BF}_{4}{ }^{-}
$$

Interestingly, this order indicates that $\mathrm{BF}_{4}^{-}$and the anion derived from $\mathrm{BF}_{3} \mathrm{OEt}_{2}$ exert very different influences on the propagation.

In Table IV are compared the $T_{\mathrm{p}}$ value and the ionic radius of the counteranion. The anion size is expressed by the sum of the bond length of metal halides and the van der Waals radius of the halogen atom involved. The latter data are summarized in Table V. It is of particular interest that the $T_{p}$ value and the anion size are correlated nicely except for $\mathrm{SnCl}_{5}{ }^{-}$.

Table IV. The size of counteranions and the precipitation temperature of polymer

\begin{tabular}{lccccc}
\hline & \multicolumn{5}{c}{ Counteranion } \\
\cline { 2 - 6 } & $\mathrm{SnCl}_{5}{ }^{-}$ & $\mathrm{SbCl}_{6}{ }^{-}$ & $\mathrm{AlBr}_{4}{ }^{-}$ & $\mathrm{AlCl}_{4}{ }^{-}$ & $\mathrm{BF}_{4}{ }^{-}$ \\
\hline Ionic radius, $\AA$ & $4.10-4.20$ & 4.23 & 4.23 & 3.96 & 2.78 \\
$T_{\mathrm{p}}$ of the polymer obtained in & -5 & $-13,-15$ & -13 & $-20,-21$ & -25 \\
$n$-hexane-- $\mathrm{CH}_{2} \mathrm{Cl}_{2}(80: 20),{ }^{\circ} \mathrm{C}$ & & -23 & -27 & -34 & -38 \\
$T_{\mathrm{p}}$ of the polymer obtained in & -18 & & & & \\
$n$-hexane- $\mathrm{CH}_{2} \mathrm{Cl}_{2}(50: 50),{ }^{\circ} \mathrm{C}$ & & &
\end{tabular}

Table V. Bond length and van der Waals radii

\begin{tabular}{|c|c|c|c|}
\hline \multicolumn{2}{|l|}{ Bond length, ̊ } & \multicolumn{2}{|c|}{$\begin{array}{c}\text { Van der } \\
\text { Waals raddi }\end{array}$} \\
\hline $\mathrm{Al}-\mathrm{Cl}$ in $\mathrm{Na}^{+} \mathrm{AlCl}_{4}^{-}$ & $2.13^{\mathrm{a}}$ & F & 1.35 \\
\hline $\mathrm{Al}-\mathrm{Br}$ & $2.28^{b}$ & $\mathrm{Cl}$ & 1.80 \\
\hline $\begin{array}{l}\mathrm{B}-\mathrm{F} \text { in }\left(\mathrm{CH}_{3}\right)_{3} \mathrm{NBF}_{3} \\
\text { and } \mathrm{BF}_{4}^{-}\end{array}$ & $1.41-1.43^{\mathrm{c}}$ & $\mathrm{Br}$ & 1.95 \\
\hline $\mathrm{Sb}-\mathrm{Cl}$ in $\mathrm{SbCl}_{5}$ & $2.43^{\mathrm{d}}$ & & \\
\hline $\mathrm{Sn}-\mathrm{Cl}$ in $\mathrm{R}^{+} \mathrm{SnCl}_{5}-$ & $2.30-2.40^{\mathrm{e}}$ & & \\
\hline
\end{tabular}

a N. C. Baenziger, Acta Cryst., 4, 216 (1951).

b Average of the two kinds of $\mathrm{Al}-\mathrm{Br}$ bonds in $\mathrm{Al}_{2} \mathrm{Br}_{6}$.<smiles>Br[Al](Br)[Al](Br)Br</smiles>
$\alpha, 2.22 \AA$

$\beta, 2.33 \AA$

For $\mathrm{Al}_{2} \mathrm{Cl}_{6} \alpha=2.06 \AA$ and $\beta=2.21 \AA$. The average bond length is $2.14 \AA$ in good agreement with $\mathrm{Al}-\mathrm{Cl}$ bond length in $\mathrm{NaAlCl}_{4}$. The bond lengths for the dimers are given in R. Kiriyama, "Kozo Muki Kagaku (Structural Inorganic Chemistry)," Vol. II, Kyoritsu-shuppan, Tokyo, 1953.

c F. A. Cotton and G. Wilkinson, "Advanced Inorganic Chemistry. A Comprehensive Text," Interscience Publishers, New York, N.Y., 1962.

d See footnote $\mathrm{b}$ for reference.

e R. F. Bryan, J. Amer. Chem. Soc., 86, 733 (1964).

f L. Pauling, "The Nature of the Chemical Bond," 3rd ed. Cornell University Press, Ithaca, N.Y., 1960 .
In the above-mentioned model we assumed that the catalyst effect could be described by the difference in the direction of monomer attack which is determined by the tightness of the growing ion-pair. If the tightness was assumed to be determined mainly by the coulombic interaction between ions, it should decrease with increasing ionic radii of the counteranion, resulting in the decrease in the content of the isotactic unit in the polymer. This is contrary to the experimental results. It is conceivable that the steric effect of the counteranion played an important role in determining the steric course of propagation. With sufficiently tight ion-pairs, the ease of the front-side attack may diminish with increasing bulkiness of the counteranion, thus enhancing the amount of the isotactic unit. The increased size of the counteranion may also contribute to the conformational stability of the growing segment, leading to better stereoregularity.

The influence of the $\mathrm{SnCl}_{5}{ }^{-}$counteranion on $T_{\mathrm{p}}$ is interesting. This anion gives rise to higher $T_{\mathrm{p}}$ values than expected from its ionic radius. Furthermore, the $T_{\mathrm{p}}$ value of the polymer obtained with this anion was high $\left(-32^{\circ} \mathrm{C}\right)$ relative to others $\left(-50 \pm 5^{\circ} \mathrm{C}\right)$ in polar $\mathrm{CH}_{2} \mathrm{Cl}_{2}$ solvent. These results suggest that the $\mathrm{SnCl}_{5}{ }^{-}$ion-pair is much tighter than other ion-pairs in a given 
solvent. This interesting property of the $\mathrm{SnCl}_{5}{ }^{-}$ anion is probably related to its pentacoordination state, in contrast with the fully coordinated other anions, as also mentioned in the following paper. ${ }^{30}$

In conclusion, the role of counteranions in affecting the steric structure appears to be interpreted in a relatively straightforward way. Since the steric structure was estimated by the $T_{\mathrm{p}}$ value, a direct relation between the property of counteranions and the polymer steric structure could not be established. However, the order of counteranions observed in this study was identical with that found in the cationic polymerization of $\alpha$-methylstyrene ${ }^{30}$ where the steric structure can be determined quantitatively. Therefore, the steric influence of the counteranion on the steric course may be a phenomenon of general significance.

\section{REFERENCES}

1. e.g., J. Smid, "Structure and Mechanism in Vinyl Polymerization," T. Tsuruta and K. O'Driscoll Ed., Marcel Dekker, Inc., New York N.Y., 1969, p 345.

2. D. D. Eley and A. W. Richards, Trans. Faraday Soc., 45, 425 (1949).

3. T. G. Bonner, J. M. Clayton, and G. Williams, J. Chem. Soc., 1705 (1958).

4. C. E. H. Bawn, C. Fitzsimmons, and A. Ledwith, Proc. Chem. Soc., 391 (1964).

5. M. S. Sambhi and F. E. Treloar, J. Polym. Sci., Part B, 3, 445 (1965).

6. M. S. Sambhi, Macromolecules, 3, 351 (1970).

7. T. Higashimura, T. Fukushima, and S. Okamura, J. Macromol. Sci. -Chem., A1, 683 (1967).

8. C. Aso, T. Kunitake, Y. Matsuguma, and Y. Imaizumi, J. Polym. Sci., Part A-1, 6, 3049 (1968).

9. N. G. Gaylord and M. Švestka, J. Makromol. Sci. -Chem., A3, 897 (1969).
10. G. Sauvet, J. P. Vairon, and P. Sigwalt, J. Polym. Sci., Part A-1, 7, 987 (1969).

11. T. Kunitake and C. Aso, ibid., Part $A-1,8$, 665 (1970).

12. H. J. Dauben, Jr., L. R. Honnen, and K. M. Harmon, J. Org. Chem., 25, 1442 (1960).

13. W. E. Bachmann, "Organic Synthesis,"' Collection Vol. 3, John Wiley \& Sons, New York, N.Y., 1955, p 841.

14. K. D. Berlin, L. H. Gowen, J. W. White, D. E. Gibbs, and G. P. Sturm, J. Org. Chem., 27, 3595 (1962).

15. D. W. A. Sharp and N. Sheppard, J. Chem. Soc., 674 (1957).

16. D. E. H. Jones and J. L. Wood, Spectrochim. Acta, 23A, 2695 (1967).

17. W. M. Pasika, Tetrahedron, 22, 557 (1966).

18. I. R. Beattie and M. Webster, J. Chem. Soc., 38 (1963).

19. J. C. Thomas, S. T. Bowden, and W. J. Jones, ibid., 478 (1930).

20. B. P. Susz and J. J. Wuhrmann, Helv. Chim. Acta, 40, 722 (1957).

21. K. M. Harmon and A. B. Harmon, J. Amer. Chem. Soc., 83, 865 (1961).

22. A. G. Evans, J.A. G. Jones, and G. O. Osborne, J. Chem. Soc., 3803 (1954).

23. D. G. Farnum, J. Amer. Chem. Soc., 86, 934 (1964).

24. S. Okamura, T. Higashimura, and I. Sakurada, J. Polym. Sci., 39, 507 (1959).

25. J. P. Kennedy, ibid., 38, 263 (1959).

26. Y. Ishimoto, Master Thesis, Faculty of Engineering, Kyushu University, 1967.

27. C.E. Schildknecht, A.Z. Zoss, and C. McKinley, Ind. Eng. Chem., 39, 180 (1947); C. E. Schildknecht, ibid., 50, 107 (1958).

28. K. Iwasaki, J. Polym. Sci., 56, 27 (1962).

29. T. Higashimura, T. Kodama, and S. Okamura, Kobunshi Kagaku (Chem. High Polymers), 17, 163 (1960).

30. Y. Matsuguma and T. Kunitake, Polymer $J$. 2, 353 (1971). 